\title{
Blocking Memory Reconsolidation Reverses Memory- Associated Changes in Glutamate Receptor Expression
}

\author{
Jacqueline K. Rose and Catharine H. Rankin \\ Department of Psychology and Brain Research Centre, University of British Columbia, Vancouver, British Columbia, Canada V6T 2B5
}

\begin{abstract}
It has been reported that consolidated memories can return to a labile state when reactivated and undergo a process of re-storage, termed reconsolidation, required for later recall. We investigated memory for a nonassociative learning task (habituation) and found that memory for this task also undergoes reconsolidation after recall. To investigate reconsolidation, we first demonstrated that adult Caenorhabditis elegans are capable of reliable memory $48 \mathrm{~h}$ after habituation training $(p<0.05)$. When heat shock was administered immediately after a reminder, response magnitudes of trained animals matched response levels of untrained animals: the inhibitory effects of heat shock on protein synthesis disrupted memory reconsolidation. Pharmacological blockade of non-NMDA-type glutamate receptors during reminder also eliminated $48 \mathrm{~h}$ retention. When expression levels of a specific glutamate receptor subunit (GLR-1) (40\% homology to mammalian AMPA-type glutamate receptors) (Hart et al., 1995; Maricq et al., 1995) were measured $48 \mathrm{~h}$ after training, there was a significant decrease in trained compared with untrained controls. If trained worms were given a reminder followed immediately by heat shock, the effect of training on GLR-1 levels was reversed. From these studies, we conclude that both the behavioral expression of long-term memory for habituation and a cellular correlate of that memory (the alteration in expression levels of GLR-1) in C. elegans can be altered after retrieval. Furthermore, conditions that impair memory consolidation similarly disrupt memory reconsolidation, suggesting that similar mechanisms are involved.
\end{abstract}

Key words: habituation; reconsolidation; memory; glutamate receptors; C. elegans; retrieval-dependent amnesia

\section{Introduction}

The phenomenon of retrieval-dependent amnesia in which retrieval of a memory made it sensitive to disruption was studied intensively in the 1960s and 1970s (for review, see Sara, 2000; Dudai and Eisenberg, 2004). More recently, Przybyslawski and Sara (1997) reported that memory is disrupted if NMDA receptors are blocked at reactivation. As well, Nader et al. (2000) found that long-term memory for fear conditioning could be abolished after retrieval by blocking reconsolidation with protein synthesis inhibitors. This work has lead many researchers to study reconsolidation, but most have focused on memory for associative learning in either classical or instrumental conditioning (Milekic and Alberini, 2002; Sangha et al., 2003; Inda et al., 2005; Merlo et al., 2005). In this paper, we examine whether memory for the most basic form of learning (habituation) also undergoes reconsolidation. Habituation is a nonassociative learning process in which a decrease in response is seen to a repeatedly presented stimulus (Groves and Thompson, 1970). Long-term memory for habituation is reflected as a long-term decrease (days to weeks) in responding after training (Carew et al., 1972).

Received May 12, 2006; revised Sept. 28, 2006; accepted Sept. 29, 2006.

This work was funded by an operating grant from the Natural Sciences and Engineering Research Council of Canada (NSERC) (C.H.R.) and by graduate fellowships from NSERC, the Michael Smith Foundation for Health Research, and the Canadian Institutes of Health Research (J.K.R.). We thank Lianne Tang for help with running and scoring some of the experiments.

Correspondence should be addressed to Dr. Catharine Rankin, Brain Research Centre, 2211 Wesbrook Mall, University of British Columbia, Vancouver, British Columbia, Canada V6T 2B5. E-mail: crankin@psych.ubc.ca. DOI:10.1523/JNEUROSCI.2049-06.2006

Copyright $\odot 2006$ Society for Neuroscience $\quad$ 0270-6474/06/2611582-06\$15.00/0
We investigated memory reconsolidation for long-term memory for habituation in an organism that has a relatively small and well studied nervous system, the nematode Caenorhabditis elegans. The nervous system of C. elegans has been mapped using electron microscopy and is made up of 302 neurons that make $\sim 5000$ chemical synapses and 2000 gap junctions (White et al., 1986). Previously, we reported that memory consolidation for habituation of the tap response (the worm swims backward in response to a mechanical stimulus to the Petri plate) in C. elegans is disrupted by heat shock, requires intact glutamate transmission, and depends on a specific subunit of a non-NMDA-type glutamate receptor, glr-1 (Rose et al., 2002, 2003). As well, using green fluorescent protein (GFP), a fluorescent genetic marker, fused to the $g l r-1$ gene to quantify changes in gene expression within a specific neural circuit, we found that GLR-1::GFP expression decreased $24 \mathrm{~h}$ after habituation training and that this decrease was also sensitive to heat shock (Rose et al., 2003).

In the experiments reported here, we used a modified version of our established long-term memory protocol to first determine that C. elegans demonstrated memory for training $48 \mathrm{~h}$ after training. We then examined reconsolidation by administering a reminder treatment (reexposure to the previously habituated stimulus) $24 \mathrm{~h}$ after training and measuring retention $48 \mathrm{~h}$ after training. To examine the effects of reconsolidation blockade, heat shock was delivered after the reminder. We also investigated whether, like consolidation, reconsolidation required activation of glutamate receptors by applying the non-NMDA-type glutamate receptor antagonist 6,7-dinitroquinoxaline-2,3-dione 
(DNQX). Finally, we measured the effect of delivering heat shock during reconsolidation on GLR-1 expression levels $24 \mathrm{~h}$ later. Our results indicated that long-term memory for habituation was sensitive to reconsolidation blockade and that a cellular correlate for the memory for habituation, a decrease in GLR-1 receptor expression, was also sensitive to disruption after a reminder.

\section{Materials and Methods}

Animals. Worms were maintained on nematode growth medium agar seeded with Escherichia coli (OP50) (Brenner, 1974). N2 C. elegans Bristol (N2) were obtained from the Caenorhabditis Genetics Center (University of Minnesota, Minneapolis, MN), GLR-1::GFP was from A. Hart (Harvard University, Boston, MA), and ${ }_{\mathrm{p}} m e c-7:: \mathrm{SNB}-1:: \mathrm{GFP}$ was from $\mathrm{M}$. Nonet (Washington University, St. Louis, MO).

Behavior. Habituation stimuli (taps) were delivered using a Grass Instruments (Quincy, MA) S88 stimulator driving a mechanical tapper exerting 1-2 $\mathrm{N}$ of force to the side of the Petri plate. Reconsolidation studies used a modified version of a previously established long-term habituation training protocol (Rose et al., 2002). Briefly, 10-15 3-d-old worms were placed on E. coli seeded Petri plates $12-18 \mathrm{~h}$ before training. On the training day, experimental worms were given distributed habituation training [four blocks of 20 taps at a $60 \mathrm{~s}$ interstimulus interval (ISI) separated by $1 \mathrm{~h}$ rest periods]; control worms were given a single tap. Reminder training, $24 \mathrm{~h}$ after original training, was 10 taps at a $60 \mathrm{~s}$ ISI; worms were transferred $1 \mathrm{~h}$ after the reminder onto individual $E$. coli streaked plates. Testing consisting of 10 taps at a $60 \mathrm{~s}$ ISI occurred $46-50$ $\mathrm{h}$ after the original training. The responses to the 10 test taps were recorded and scored for data analysis. All behavioral data were scored using stop-frame video analysis to trace the distance traveled backward to each tap onto acetate sheets. Tracings were scanned into the computer and measured using NIH Image software. Occasionally, worms swam rapidly forward in response to tap; these accelerations forward are qualitatively different from reversals and were scored as missing data points $(<10 \%$ of the data).

Heat shock. Plates were double sealed with Parafilm and submerged in $32^{\circ} \mathrm{C}$ water for $40 \mathrm{~min}$ immediately after reminder training or at $24 \mathrm{~h}$ after training in groups in which no reminder was given. The cellular response to heat shock is to dedicate transcription and translation machinery to selectively produce heat shock proteins (HSPs) (Lindquist, 1986; Dubois et al., 1999). This response to heat shock is to prevent apoptosis and is thought to be triggered by an increase in denatured or misfolded proteins resulting from heat or other cell stressors. HSPs (or molecular chaperones) have two roles: they refold misfolded proteins or intermediate polypeptides or they can act like a protease and mark severely damaged proteins for degradation. When the number of HSPs reaches some critical level, the HSPs act on their own heat shock transcription factors, resulting in the cessation of HSP production (for review, see Morimoto and Santoro, 1998). One advantage of using heat shock to disrupt de novo protein synthesis is that heat shock blockade of protein synthesis can be applied for a discrete period of time (i.e., for 40 min after training). During heat shock, cellular protein synthesis mechanisms remain intact (the heat shock response itself is inhibited in the presence of the transcription blocker cycloheximide) (Amici et al., 1992). When heat stress is removed, cells return to normal very quickly: the production and cessation of heat shock proteins occurs on the order of minutes (Morimoto and Santoro, 1998). As well, heat shock is nontoxic to worms [pharmacological protein synthesis inhibitors typically produce behaviorally lethargic worms likely attributable to drug toxicity (our unpublished observations)] and heat shock is a non-intrusive method of arresting protein synthesis that uses a natural response to stress (Lindquist, 1986).

Pharmacology. For experiments involving DNQX, drug was dissolved in $35 \mathrm{~mm} \mathrm{NaOH}$ to prepare $10 \mathrm{~mm}$ DNQX, a dose shown previously to block long-term memory formation if worms are exposed during training. Two hours before training, $500 \mu \mathrm{l}$ of either $10 \mathrm{~mm}$ DNQX or $35 \mathrm{~mm}$ $\mathrm{NaOH}$ (vehicle) was placed onto the surface of agar plates bearing E. coli. For the drug groups, $500 \mu \mathrm{l}$ of $10 \mathrm{~mm}$ DNQX applied to $10 \mathrm{ml}$ of agar made the effective external concentration in the worm's environment
$476 \mathrm{~mm}$. One hour before reminder training ( $\sim 24 \mathrm{~h}$ after training), two groups of 10-15 4-d-old N2 worms were transferred to drug-treated plates, and another two groups were transferred to vehicle-treated plates. All worms were given 10 taps at a $60 \mathrm{~s}$ ISI and were transferred $1 \mathrm{~h}$ later to individual drug-free plates. Testing occurred the next day (48 h after training) with 10 taps (at a $60 \mathrm{~s}$ ISI). Drug exposure was $<3 \mathrm{~h}$, and all testing was conducted $\geq 20 \mathrm{~h}$ after removal of drug. To test whether memory for training was intact after reminder on DNQX, a group of trained and control worms were given the 10 reminder taps on DNQX $24 \mathrm{~h}$ after training. Worms remained on DNQX for $40 \mathrm{~min}$ after the reminder and were then transferred to drug-free plates and given $20 \mathrm{~min}$ to recover before all worms were given 5 taps at a $60 \mathrm{~s}$ ISI to assess memory.

Imaging. For imaging, GFP transgenic worm strains were mounted onto welled slides using $15 \mu \mathrm{l}$ of 2,3-butanedione monoxime for paralysis mixed with medium Sephadex beads to prevent worms from being crushed. An inverted Zeiss (Toronto, Ontario, Canada) Axiovert with differential interference contrast optics microscope with a Bio-Rad (Hercules, CA) Radiance Plus confocal system equipped with an argon laser was used for imaging. GFP was excited using a $488 \mathrm{~nm}$ wavelength laser setting. Images were captured in a $512 \times 512$ pixel field of view, with optical sections collected at $0.5 \mu \mathrm{m}$ intervals using a $63 \times$ oil lens.

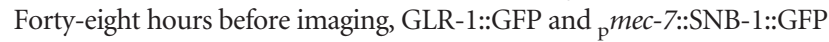
worms were given taps in the distributed training protocol or the singletap control. At $24 \mathrm{~h}$ after training, all worms received 10 taps as reminder training, followed immediately by either heat shock or no shock. In another experiment, the same procedure was followed, but no reminder was given.

The GLR-1::GFP strain expressed GFP along the ventral cord, and images were collected along the posterior portion from the tail to the vulva. Images of GLR-1::GFP expression were composed of 12-30 optical sections. A researcher blind to the treatment groups coded imaging files. GFP expression was determined from collected images using NIH Image 1.63. $Z$ projections were compiled and thresholded, and areas of GFP expression were measured as square micrometers. Number of GFP clusters were also tallied.

Transgenic worms carrying pec- $_{\mathrm{p}}: \mathrm{SNB}-1:$ GFP typically display two patches of GFP expression just posterior to the vulva (Nonet, 1999). GFP expressed in the ${ }_{\mathrm{p}}$ mec-7::SNB-1::GFP worms was captured in a single image composed of $\sim 15-35$ optical sections. A researcher blind to the treatment groups coded the image files. In NIH Image $1.63, Z$ projections were compiled and thresholded, and areas of GFP expression were measured as square micrometers. Final figures were generated using Adobe Photoshop 7.0 (Adobe Systems, San Jose, CA).

Data analysis. Response magnitudes and measures of GFP expression were compared between groups using one-way ANOVA procedures. Fisher's least significant difference was used for post hoc analyses.

\section{Results}

\section{Adult C. elegans show 48 h memory}

In previous studies, memory testing occurred $24 \mathrm{~h}$ after training (Rose et al., 2002, 2003). In this experiment, we extended the retention interval to $48 \mathrm{~h}$, a significant time period considering the short lifespan of C. elegans $(\sim 12 \mathrm{~d}$ ) (Fig. $1 A$ ). To test whether this memory would last longer than $24 \mathrm{~h}, 4$-d-old adult worms were given long-term habituation training, whereas control worms were given a single tap. We found that, $48 \mathrm{~h}$ after training, trained adult $C$. elegans showed significantly smaller responses at test compared with untrained controls $\left(F_{(3,62)}=4.978 ; p<0.01\right)$. Heat shock (used to compromise de novo protein synthesis; see Materials and Methods) (Rose et al., 2002, 2003) delivered alone $24 \mathrm{~h}$ after training had no effect on this $48 \mathrm{~h}$ memory (Fig. $1 \mathrm{~A}, B$ ) because there remained a significant difference in response magnitude between the control and trained groups that received heat shock $(p=0.029)$. 

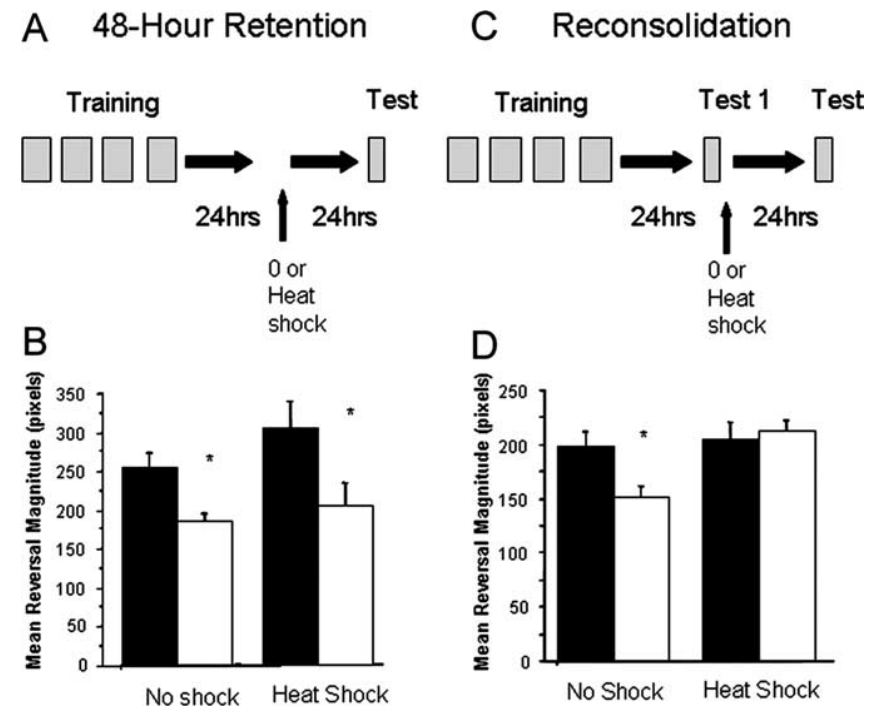

Figure 1. Long-term memory for habituation is sensitive to reconsolidation blockade. The mean reversal magnitude in response to a mechanosensory stimulus was measured for either control (black bars) or trained (white bars) worms. $\boldsymbol{A}$, Retention protocol: trained worms received four blocks of 20 taps delivered at a 60 s ISI and testing (10 taps at a 60 s ISI). B, Mean \pm SEM response to tap across the 10 test taps in worms that received either heat shock or no shock during the retention interval. C, Reconsolidation protocol; same as above except worms receive reminder training ( 10 taps delivered at a 10 s ISI) $24 \mathrm{~h}$ after training. D, Mean \pm SEM response to tap across the 10 test taps in worms that received reminder immediately followed by either heat shock or no shock. ${ }^{*} p<0.05$.

The $48 \mathrm{~h}$ memory is sensitive to reconsolidation blockade Because worms were able to show retention $48 \mathrm{~h}$ after training, we were able to design a paradigm to test whether memory for nonassociative learning (i.e., habituation) undergoes reconsolidation after retrieval. Four-day-old worms were first given distributed training followed $24 \mathrm{~h}$ later by a reminder (10 taps at a $60 \mathrm{~s} \mathrm{ISI)}$ and then tested $24 \mathrm{~h}$ after the reminder (Fig. $1 C$ ). One group of control and trained worms received only the reminder $24 \mathrm{~h}$ after training, and the other group received the reminder immediately followed by heat shock to disrupt any reconsolidation process activated by memory retrieval. For the $48 \mathrm{~h}$ retention test, there was a significant difference in response magnitude among the four groups $\left(F_{(3,81)}=4.569 ; p=0.005\right)$. Specifically, trained worms showed significantly smaller responses to the 10 test taps than control worms $(p=0.012)$. In contrast, the control and trained groups that experienced the reminder followed by heat shock showed no difference in responding at $48 \mathrm{~h}(p=0.719)$, suggesting that memory for the original training was no longer being expressed. Thus, like memory for associative learning, memory for habituation is similarly vulnerable to interference of reconsolidation.

\section{Reconsolidation also blocked by DNQX}

Application of the non-NMDA-type glutamate receptor antagonist DNQX during training blocked the formation or consolidation of long-term memory and the downregulation of glr-1containing receptors (Rose et al., 2002, 2003). In this study, we examined whether the presence of DNQX during memory reactivation would affect later recall. First we determined whether DNQX affected memory retention in the absence of a reminder; standard trained and control groups were exposed to either 35 $\mathrm{mm} \mathrm{NaOH}$ (vehicle) or $10 \mathrm{~mm}$ DNQX (a dose shown to be sufficient to block long-term memory if given during training) (Rose et al., 2003) $24 \mathrm{~h}$ after training with no reminder. When worms
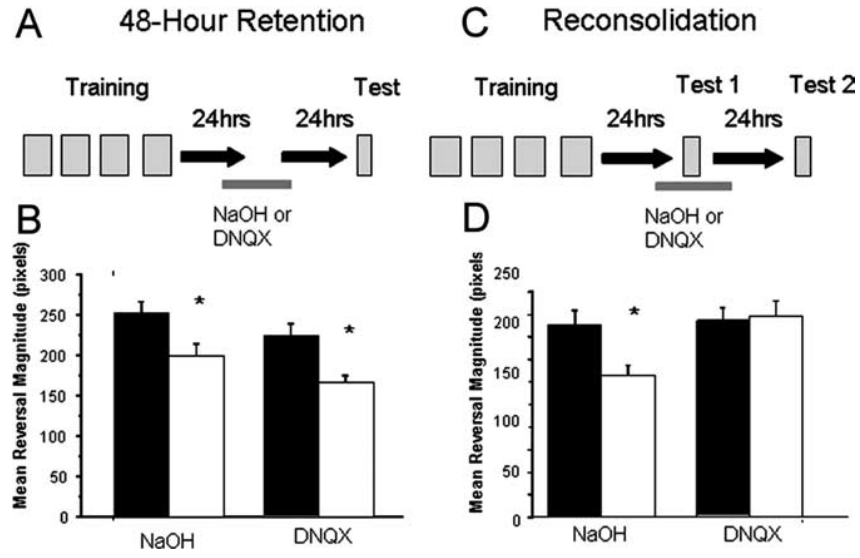

Figure 2. Reconsolidation requires non-NMDA-type glutamate receptor activation. $\boldsymbol{A}$, Drug retention protocol; same as described previously, but both control (black bars) and trained (white bars) worms are exposed to either DNQX or vehicle $24 \mathrm{~h}$ after training for $130 \mathrm{~min}$. $\boldsymbol{B}$, Mean \pm SEM response to tap across 10 test taps by trained and control worms that received either DNQX or vehicle $24 \mathrm{~h}$ after training. C, Drug reconsolidation protocol; worms are exposed to either DNQX or vehicle for the hour before, during, and after reminder. D, Mean \pm SEM response to tap across the 10 test taps in worms that received reminder in the presence of either DNQX or vehicle. ${ }^{*} p<0.05$.

were tested $48 \mathrm{~h}$ after training (Fig. $2 \mathrm{~A}$ ), significant retention of memory was seen, regardless of whether the worms were treated with $\mathrm{NaOH}$ or DNQX (Fig. $2 B)\left(F_{(3,67)}=6.103 ; p=0.001\right.$ ). Trained worms exposed to vehicle alone without reminder showed significantly smaller responses to test taps than control worms $(p=0.016)$. As well, trained worms exposed to DNQX without reminder showed significantly smaller responses to the test taps than did control worms $(p=0.008)$. Thus, without a reminder, neither vehicle alone nor DNQX had any effect on $48 \mathrm{~h}$ retention.

To determine whether DNQX affected memory retention if delivered during the reminder period, trained and control groups were exposed again to either $35 \mathrm{~mm} \mathrm{NaOH}$ (vehicle) or $10 \mathrm{~mm}$ DNQX $24 \mathrm{~h}$ after training, with a reminder given during drug exposure. Worms were tested for retention $24 \mathrm{~h}$ later (Fig. 2C), and significant differences were seen (Fig. $2 D)\left(F_{(3,103)}=4.090\right.$; $p=0.009)$; when vehicle was administered with the reminder, there was still significant retention $48 \mathrm{~h}$ after training $(p=$ 0.011). However, when non-NMDA-type glutamate receptors were blocked by DNQX during the reminder period, there was no significant difference between trained and control worms $(p=$ $0.822) 48 \mathrm{~h}$ after training. As a control, we tested whether worms that received the reminder on DNQX would still show the memory a short time after the reminder during drug exposure. We tested whether trained and control worms that received the reminder on DNQX would show memory $\sim 2 \mathrm{~h}$ after the reminder (testing began $20 \mathrm{~min}$ after removal from DNQX). We found that memory was still intact: trained worms that received reminder on DNQX still showed smaller responses than untrained worms that received reminder on $\operatorname{DNQX}\left(t_{(44)}=2.522 ; p=0.015\right)$. Together, these data show that exposure to DNQX alone (with no reminder) could not account for the blockade of memory noted when DNQX was administered during memory reactivation and reconsolidation. Thus, similar to the initial memory process, reconsolidation also requires the activation of non-NMDA-type glutamate receptors. These data demonstrate that the same glutamate-dependent plasticity required for long-term memory is also involved in reestablishing previously consolidated memory. 
A 48-Hour Retention

C Reconsolidation
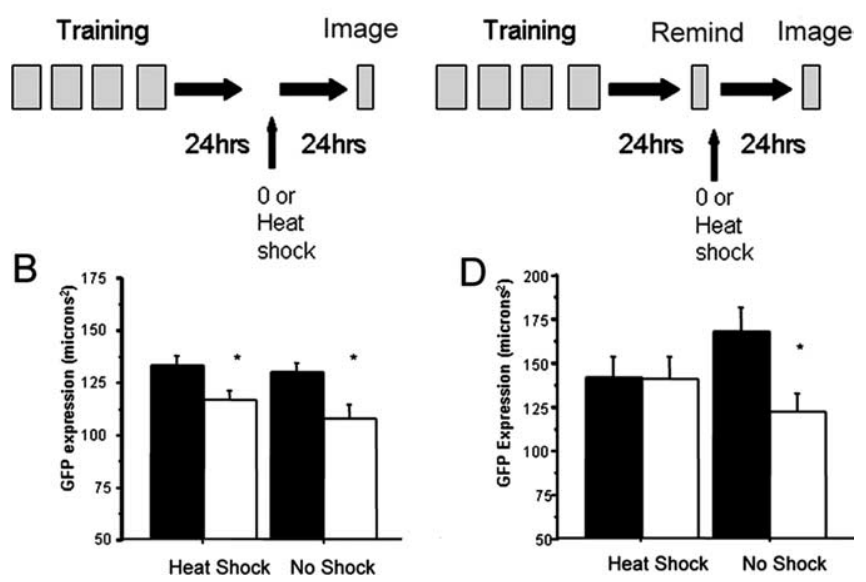

Figure 3. GLR-1::GFP expression is sensitive to reconsolidation blockade. $A$, GLR-1::GFP expression was measured after confocal imaging at $48 \mathrm{~h}$ after training. $\boldsymbol{B}$, Mean \pm SEM of total GLR-1::GFP expression between control (black bars) and trained (white bars) worms with no reminder and either heat shock or no shock. C, Protocol for confocal imaging after reminder. $\boldsymbol{D}$, Mean \pm SEM of total GLR-1::GFP expression in worms that received the reminder followed by either heat shock or no shock. ${ }^{*} p<0.05$.

\section{Reconsolidation blockade affects GLR-1::GFP distribution}

Our results with DNQX suggested that glutamate receptors play a critical role in the reconsolidation process. In our studies of longterm memory consolidation, we found that expression of glutamate receptors containing the $g l r-1$ subunit was altered $24 \mathrm{~h}$ after habituation training (Rose et al., 2003). This was shown using a transgenic strain of worms carrying a genetic construct comprising the glr-1 gene tagged with GFP. When these GLR-1::GFP worms received habituation training $24 \mathrm{~h}$ before imaging, there was significantly less GLR-1::GFP expression compared with control worms (Rose et al., 2003). For the current study, we first demonstrated that the decrease in GLR-1::GFP lasts $48 \mathrm{~h}$. To show this, we trained worms containing the GLR-1::GFP construct with the long-term habituation training protocol followed $48 \mathrm{~h}$ later by confocal imaging of the GLR-1::GFP construct. A second group followed the same procedure but was given heat shock $24 \mathrm{~h}$ after training with images taken $24 \mathrm{~h}$ after that. Worms still showed significantly less GLR-1::GFP in trained groups than in control groups $48 \mathrm{~h}$ after training regardless of whether heat shock was administered $24 \mathrm{~h}$ after training (Fig. $3 A)\left(F_{(3,32)}=\right.$ $3.980 ; p=0.016)$. Thus, like the behavioral expression of longterm memory for habituation, the decrease in GLR-1::GFP seen $24 \mathrm{~h}$ after distributed habituation training is still present $48 \mathrm{~h}$ after training. Heat shock delivered $24 \mathrm{~h}$ after training did not disrupt the decrease in GLR-1::GFP seen 48 h later $(p=0.007)$.

Next we tested the effect of reminder training on the distribution of GLR-1::GFP. Twenty four hours after training, one group of trained and control worms were given just the reminder taps, and the other group of trained and control worms received the reminder taps followed immediately by heat shock. Twenty-four hours after the reminder, we imaged and measured GLR-1::GFP expression and found a significant difference in GLR-1::GFP expression between groups that received the reminder (Fig. $3 B$ ) $\left(F_{(3,38)}=3.248 ; p<0.032\right)$; trained worms showed significantly less GLR-1::GFP expression than controls (Fig. $3 A)(p<0.004)$. However, if trained worms received heat shock immediately after the reminder, this eliminated the difference in GLR-1::GFP expression $(p<0.972)$. In fact, blockade of reconsolidation after reminder appeared to reset GLR-1::GFP expression to the same levels as seen with control worms that never received training. Because trained worms given heat shock with no reminder did show a decrease in GLR-1::GFP expression whereas worms given heat shock after the reminder did not show the difference in GLR-1::GFP expression, we conclude that the reactivation of the memory made the distribution of GLR-1::GFP labile and subject to reconsolidation blockade.

In our previous studies of long-term memory for habituation, we determined that, $24 \mathrm{~h}$ after training, there was no change in the number of GLR-1::GFP clusters, but there was a significant difference in overall GLR-1::GFP expression. Based on this finding, we hypothesized that the number of synapses were not altered by training; rather, training decreased the average amount of GLR-1::GFP per synapse. Similarly, in this experiment, we found no significant differences in the number of GFP clusters $\left(F_{(3,42)}=1.506 ; p=0.227\right)$ among any of our trained and control groups. This supports our previous hypothesis that the decrease in GLR-1::GFP expression does not reflect fewer connections. As in our previous research on long-term memory for habituation, these results show a strong association between the behavioral expression of memory and the expression levels of GLR-1::GFP.

In our previous studies of long-term memory in C. elegans (Rose et al., 2003), we showed that there were no changes in the expression of a fluorescently tagged presynaptic marker (synaptobrevin) in the touch cells after long-term habituation training. Using the same transgenic strain of $C$. elegans (GFP fused to the SNB-1 gene; codes for the vesicular protein synaptobrevin) with a mec-7 promoter ( ${ }_{\mathrm{p}}$ mec-7::SNB-1::GFP) so expression was restricted to the mechanosensory neurons, we found similar results in our reconsolidation paradigm. There were no differences in SNB-1::GFP expression between trained worms and controls $48 \mathrm{~h}$ after training $\left(F_{(3,39)}=2.186 ; p=0.105\right)$. Similarly, there was no change in $\mathrm{p}_{\mathrm{p}} \mathrm{c}-7:: \mathrm{SNB}-1:: \mathrm{GFP}$ expression when reminder training was administered $24 \mathrm{~h}$ after initial training $\left(F_{(3,42)}=1.506\right.$; $p=0.227$ ), suggesting that, like consolidation, reconsolidation does not result in long-lasting changes in presynaptic synaptobrevin expression.

\section{Discussion}

Using a nonassociative learning task, this study demonstrates that heat shock delivered immediately on memory reactivation interferes with later memory recall. These results confirm that retrieval-activated amnesia of a previously established memory is a consistent memory phenomenon found not just for associativelearning tasks but also for nonassociative tasks, in this case, habituation. This implies that memory that relies on simple neural circuits is also subject to modification after retrieval, suggesting that this may be a general phenomenon of neural plasticity.

As we showed for consolidated memory (Rose et al., 2003), reconsolidation of a previously established memory requires activation of non-NMDA-type glutamate receptors: no memory was seen after retrieval occurred in the presence of DNQX. This abolition of memory attributable to reactivation of the memory occurring in the presence of DNQX suggests that $g l r-1$ receptors were not necessary for the retrieval of the consolidated memory. If $g l r-1$ receptor activation were required for memory retrieval, then exposure to DNQX during reminder would have prevented memory reactivation: the memory would not have returned to a labile state and therefore could not be modified by disruption of reconsolidation. Thus, DNQX would have shown no effect on later retention. From our results, it appears that DNQX has somehow specifically blocked the re-storage of the activated or 
labile memory. The finding that DNQX likely inhibits reconsolidation in a manner similar to memory consolidation supports the conclusion that, in this paradigm, reconsolidation relies on a similar cellular mechanism as consolidation.

One of the advantages of using a habituation paradigm to study reconsolidation is that the issue of extinction is not relevant. In studies of classical or instrumental conditioning using a single cue (either the conditioned or the unconditioned stimulus) as a reminder can lead to a weakening of the association and contribute to the loss of the memory. In the case of habituation, there is no extinction, and the reminder training might, in fact, be seen as "retraining" so, if it had any effect, it should have enhanced the memory. Our data showed that, if retraining was followed by heat shock, then the original memory was no longer available. The observation that this retraining does not simply strengthen the memory but makes it more vulnerable to alterations suggests that the effects of reconsolidation blockade cannot be explained by simple extinction.

Memory for habituation has been correlated with a significant decrease in GLR-1::GFP expression with no change in expression

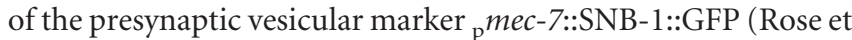
al., 2003). The decrease in GLR-1::GFP expression was shown to be sensitive to heat shock during consolidation. A similar finding was recently reported for AMPA receptor density in mammals: there was a change in AMPA receptor expression after conditioning, and, when this change was prevented, memory was inhibited (Rumpel et al., 2005). The current study demonstrated that the modification in GLR-1 expression seen with memory can be reversed when heat shock is delivered during reconsolidation: levels of GLR-1 expression return to baseline. In other words, reconsolidation may somehow serve to maintain/reinforce the modified level of GLR-1 expression set by memory consolidation because, when reconsolidation is prevented, GLR-1 expression returns to levels that match naive animals.

The findings of this series of experiments confirm the observation that GLR-1 cluster density is closely correlated with the expression of memory for habituation. That memory for habituation is mediated by a postsynaptic mechanism (receptor density) may seem to be in opposition to previous reports in the mollusk Aplysia: long-term habituation produced a decrease in presynaptic varicosities on the sensory neurons (Bailey and Chen, 1988). However, to produce this presynaptic decrease, Bailey and Chen (1988) administered much more training (10 training blocks for $10 \mathrm{~d}$ ) than was required to elicit long-term memory for habituation. The current study examined changes in GLR-1 expression that resulted after delivery of the same amount of training (four blocks on a single day) required to produce habituation behaviorally. Furthermore, this is the fourth report of changes in GLR-1::GFP expression produced by the same training protocol and on the same timescale as the behavioral changes observed (Rose et al., 2003, 2005) (C. A. Ebrahimi and C. H. Rankin, unpublished observations). This suggests that alterations in $g l r-1$ expression are a kind of "cellular signature" for the behavioral expression of memory.

There are two possible explanations for the lack of memory seen after the treatments that we referred to as "reconsolidation blockade." One possibility is that the memory has not been restored or reconsolidated and so is no longer represented in the nervous system. The other possibility is a retrieval failure in which the memory is still present in the nervous system, but cannot easily be accessed. In behavioral experiments, memory is abolished if either consolidation or reconsolidation is disrupted. Furthermore, Beck and Rankin (1995) reported that heat shock delivered before test did not block retrieval of long-term memory. At a cellular level, we report that GLR-1 expression in neurons underlying the behavior is similarly altered by the same manipulations found to modify behavior (i.e., protein synthesis interference by heat shock and non-NMDA-type glutamate receptor blockade). Therefore, for memory of habituation, consolidation and reconsolidation share several properties, indicating that, under these conditions, reconsolidation is mechanistically similar to memory consolidation. Together, these findings suggest that a block in memory re-storage or reconsolidation is occurring rather than a retrieval failure.

It is interesting to note that, when reconsolidation was blocked with heat shock after a reminder, GLR-1::GFP expression returned to levels that were the same as control worms, suggesting two things: first, that GLR-1 expression levels can increase/recover in neurons after a sustained decrease in concentration; second, that somehow the cell "remembers" what its baseline synaptic concentration of GLR-1 was before memory induction. One possible explanation is that, although we report that levels of GLR-1 expression are modified by memory, complexes responsible for moving GLR-1 to synapses may remain stable. In a 2002 review, Malinow and Malenka discuss "slot" complexes comprising synaptic scaffolding proteins associated with AMPA receptors. In another review, Malenka and Bear (2004) suggest that these "slot proteins" act as synaptic place holders for AMPA receptors. Therefore, although GLR-1 expression was altered by memory (in this case decreased), it is possible that the number of slot proteins did not change. Thus, the memory-induced decrease in GLR-1 would produce unoccupied receptor slots. When GLR-1 expression became labile after reminder and memory consolidation processes were inhibited by heat shock, this may have allowed GLR-1-containing receptors to reoccupy these empty slots. This would explain why GLR-1 expression returns to baseline levels and not more. It would be of interest in future studies to further uncover whether this is a plausible mechanism of memory modification and, if so, what determines the baseline number of receptor slots.

Memory reconsolidation has been implicated as a possible avenue for treating a variety of conditions, for instance, posttraumatic stress disorder (Dêbiec and Le Doux, 2004) and, more recently, drug addiction (Lee et al., 2005; Miller and Marshall, 2005; Milekic et al., 2006; Valjent et al., 2006). Presumably, abolishing the memory for the association between an event and the emotion or sensation of reward that is associated with that memory would be therapeutic. The data reported in this paper are the first demonstration that memory for nonassociative learning shows a similar level of plasticity after reactivation, as has been seen with memory for associative learning. In addition, this is the first demonstration that a cellular correlate of a memory (modified GLR-1 expression) is reversed when reconsolidation is blocked. By showing that nonassociative memory can be modified after consolidation and that a cellular signature of that memory can also be changed, our findings further extend the therapeutic possibilities of modifying memories.

\section{References}

Amici C, Sistonen L, Santoro MG, Morimoto RI (1992) Antiproliferative prostagladins activate heat shock transcription factor. Proc Natl Acad Sci USA 89:6227-6231.

Bailey C, Chen M (1988) Long-term memory in Aplysia modulates the total number of varicosities of single identified neurons. Proc Natl Acad Sci USA 85:2373-2377.

Beck CDO, Rankin CH (1995) Heat shock disrupts long-term memory consolidation in Caenorhabditis elegans. Learn Mem 2:161-177. 
Brenner S (1974) The genetics of Caenorhabditis elegans. Genetics 77:71-94.

Carew TJ, Pinsker HM, Kandel ER (1972) Long-term habituation of a defense withdrawal reflex in Aplysia. Science 182:1158-1160.

Dêbiec J, Le Doux JE (2004) Disruption of reconsolidation but not consolidation of auditory fear conditioning by noradrenergic blockade in the amygdala. Neuroscience 129:267-272.

Dubois MF, Marshall NF, Nguyen VT, Dahmus GK, Bonnet F, Dahmus ME, Bensaude O (1999) Heat shock of HeLa cells inactivates a nuclear protein phosphatase specific for dephosphorylation of the C-terminal domain of RNA polymerase II. Nucleic Acids Res 27:1338-1344.

Dudai Y, Eisenberg M (2004) Rites of passage of the engram: reconsolidation and the lingering consolidation hypothesis. Neuron 44:93-100.

Groves PM, Thompson RF (1970) Habituation: a dual-process theory. Psychol Rev 77:419-450.

Hart AC, Sims S, Kaplan JM (1995) Synaptic code for sensory modalities revealed by C. elegans GLR-1 glutamate receptor. Nature 378:82-85.

Inda M, Delgado-Garcia J, Carrión Á (2005) Acquisition, consolidation, reconsolidation, and extinction of eyelid conditioning responses require de novo protein synthesis. J Neurosci 25:2070-2080.

Lee JLC, Di Ciano P, Thomas KL, Everitt BJ (2005) Disrupting reconsolidation of drug memories reduces cocaine-seeking behavior. Neuron 47:795-801.

Lindquist S (1986) The heat-shock response. Annu Rev Biochem 55:1151-1191.

Malenka RC, Bear MF (2004) LTP and LTD: an embarrassment of riches. Neuron 44:5-21.

Malinow R, Malenka RC (2002) AMPA receptor trafficking and synaptic plasticity. Annu Rev Neurosci 25:103-126.

Maricq AV, Peckol E, Driscoll M, Bargmann CI (1995) Mechanosensory signaling in C. elegans mediated by the GLR-1 glutamate receptor. Nature 378:78-81.

Merlo E, Freudenthal R, Maldonado H, Romano A (2005) Activation of the transcription factor NF-kB by retrieval is required for long-term memory reconsolidation. Learn Mem 12:23-29.

Milekic M, Alberini C (2002) Temporally graded requirement for protein synthesis following memory reactivation. Neuron 36:521-525.

Milekic MH, Brown SD, Castellini C, Alberini CM (2006) Persistent disrup- tion of an established morphine conditioned place preference. J Neurosci 26:3010-3020.

Miller CA, Marshall JF (2005) Molecular substrates for retrieval and reconsolidation of cocaine-associated contextual memory. Neuron 47:873-884.

Morimoto RI, Santoro MG (1998) Stress-inducible responses and heat shock proteins: new pharmacologic targets for cytoprotection. Nat Biotechnol 16:833-838.

Nader K, Schafe G, Le Doux J (2000) Fear memories require protein synthesis in the amygdala for reconsolidation after retrieval. Nature 406:722-726.

Nonet M (1999) Visualization of synaptic specializations in live C. elegans with synaptic vesicle protein-GFP fusions. J Neurosci Methods 89:33-40.

Przybyslawski J, Sara SJ (1997) Reconsolidation of memory after its reactivation. Behav Brain Res 84:241-246.

Rose JK, Kaun KR, Rankin C (2002) A new group-training procedure for habituation demonstrates that presynaptic glutamate release contributes to long-term memory in C. elegans. Learn Mem 9:130-137.

Rose JK, Kaun KR, Chen SH, Rankin CH (2003) GLR-1, a non-NMDA glutamate receptor homolog, is critical for long-term memory in Caenorhabditis elegans. J Neurosci 23:9595-9599.

Rose JK, Sangha S, Rai S, Norman KR, Rankin CH (2005) Decreased sensory stimulation reduces behavioral responding, retards development, and alters neuronal connectivity in Caenorhabditis elegans. J Neurosci 25:7159-7168.

Rumpel S, Le Doux JE, Zador A, Malinow R (2005) Postsynaptic receptor trafficking underlying a form of associative learning. Science 308:83-88.

Sangha S, Scheibenstock A, Lukowiak K (2003) Reconsolidation of a longterm memory in Lymnaea requires new protein and RNA synthesis and the soma of right pedal dorsal 1. J Neurosci 23:8034-8040.

Sara S (2000) Retrieval and reconsolidation: toward a neurobiology of remembering. Learn Mem 7:73-84.

Valjent E, Corbille AG, Bertran-Gonzalez J, Herve D, Girault JA (2006) Inhibition of ERK pathways or protein synthesis during reexposure to drugs of abuse erases previously learned place preference. Proc Natl Acad Sci USA 103:2932-2937.

White J, Southgate E, Thomson J, Brenner S (1986) The structure of the nervous system of the nematode Caenorhabditis elegans. Philos Trans R Soc Lond B Biol Sci 314:1-340. 